\title{
Working memory differences in illusory recollection of critical lures
}

\author{
Michael T. Bixter • Frances Daniel
}

Published online: 24 January 2013

(C) Psychonomic Society, Inc. 2013

\begin{abstract}
In the present experiments, we explored the relationship between individual differences in working memory (WM) capacity and susceptibility to false recognitions and their accompanying subjective experiences. Deese/RoedigerMcDermott (DRM) associative lists were used to elicit false memories, and remember/know judgments were used to measure the recollective experiences accompanying recognition decisions. We found that WM capacity was related to false recognitions of nonpresented critical lures and to the proportion of remember responses given to critical lures, such that higher WM capacity was associated with lower falserecognition rates and with lower proportions of remember responses. Importantly, these WM differences were only found when participants were forewarned about the nature of the DRM task prior to encoding (Exp. 1). When the forewarning was absent, WM capacity was not related to false recognitions or to the proportion of remember responses given to critical lures (Exp. 2). These results support the controlledattention view of WM and suggest that subjective experiences of falsely recognized lures fluctuate as a function of WM capacity.
\end{abstract}

Keywords Working memory capacity $\cdot$ Illusory recollection - Recognition judgments $\cdot$ False memories · Remember/know

Many people often falsely remember information that was never presented to them. To measure these false memories, the Deese/Roediger-McDermott (DRM; Deese, 1959; Roediger \& McDermott, 1995) paradigm is commonly used, in which an associative list of words (e.g., nurse, sick, medicine, etc.) is presented and participants are asked to

M. T. Bixter $(\bowtie)$

Department of Psychology, Stony Brook University, Stony Brook, NY 11794-2500, USA

e-mail: michael.bixter@stonybrook.edu

F. Daniel

Indiana University Northwest, Gary, IN, USA either recall or recognize the words at a later time. On subsequent memory tests, participants often recall or recognize critical lures (e.g., doctor), which are words that are semantically related to all of the items on the presented lists but that were not themselves presented. In fact, the intrusion and false-recognition rates for critical lures have often been found to be comparable to, or sometimes even exceed, recognition rates of the studied words (e.g., Hicks \& Hancock, 2002; McDermott, 1996; Roediger \& McDermott, 1995; Seamon, Luo \& Gallo, 1998).

To explain this effect, an activation/monitoring theory of the DRM false-memory phenomenon has been proposed (Gallo, 2010; Roediger \& McDermott, 2000; Roediger, Watson, McDermott \& Gallo, 2001). According to this framework, as with other implicit-association theories of recognition memory (e.g., Underwood, 1965), the critical lure is activated during encoding by spreading activation through a semantic network. As the semantic associates of the particular DRM list are presented, this spreading activation converges upon the critical lure word, which is itself activated as a result (whether automatically or consciously). Subsequently, during the testing phase, the heightened activation of the critical lure during encoding will often cause a disruption in the participant's source monitoring (Johnson, Hashtroudi \& Lindsay, 1993). With an inability to correctly attribute the critical lure memory to its actual source, participants will often recollect or recognize the critical lure as having been previously presented.

Because of the robustness of the DRM illusion across different experiments and conditions, much research has been conducted to explore variables that could potentially eliminate, or at least reduce, the false-memory effect. One such condition, which is important for the present study, is explicitly forewarning participants about of the nature of the DRM illusion (e.g., Gallo, Roberts \& Seamon, 1997; McDermott \& Roediger, 1998; Neuschatz, Benoit \& Payne, 2003; Watson, McDermott \& Balota, 2004). The general finding of these studies has been that an explicit forewarning of the DRM illusion prior to encoding usually 
is able to reduce, though not to completely eliminate, falserecall or false-recognition rates for the critical lures. There are multiple explanations for these results. For example, with the foreknowledge of the DRM task, participants may be better able to identify critical lures during encoding and mark them in memory as lures to be rejected (an identify-toreject strategy; Carneiro, Fernandez, Diez, Garcia-Marques, Ramos \& Ferreira, 2012; Neuschatz et al., 2003). During testing, then, this strategy may be able to aid participants in their ability to correctly monitor the source of the critical lures as being internally generated, as opposed to externally presented (i.e., better reality monitoring; Johnson \& Raye, 1981). A signal detection view, on the other hand, suggests that participants who have been forewarned may adopt a more conservative criterion during testing, which would lead to reduced false-memory rates.

Recently, the relationship between working memory (WM) capacity and performance on the DRM task has been investigated (e.g., Peters, Jelicic, Verbeek \& Merckelbach, 2007; Watson, Bunting, Poole \& Conway, 2005). Watson et al. (2005) found that those with high WM capacity recalled significantly fewer critical lures than did those with low WM capacity. This WM difference only emerged, however, when participants were forewarned about the nature of the DRM task prior to encoding. No WM differences were found in recall when the forewarning was absent. Watson et al. (2005) suggested that the forewarning manipulation changes the DRM into a dual task that requires participants to encode each item on the list in an attempt to store it in memory, while simultaneously attempting to identify the critical lure of a list during encoding. WM differences are commonly found when participants have to executively allocate attention between two competing tasks while simultaneously maintaining an overarching goal (e.g., Colflesh \& Conway, 2007; Kane \& Engle, 2003). Thus, it is possible that those with high WM capacity were better able to divide their attention between the two competing tasks and were more able to identify the critical lure during encoding, to mark it as the critical lure in memory, and to more effectively monitor its source during retrieval/testing.

A controlled-attention view of WM capacity (e.g., Engle \& Kane, 2004; Kane \& Engle, 2002) explains Watson et al. (2005) findings by suggesting that WM differences emerge in the ability to keep information active (e.g., maintaining task goals) in attention-demanding situations (e.g., when a secondary load is concurrently introduced). WM capacity differences in performance are often found when the competing task leads to a habitual response that must be inhibited to achieve the current task goal (Engle \& Kane, 2004). From this perspective, it is understandable why WM capacity differences would be found in recall rates for critical lures in the forewarned DRM task: When participants were forewarned about the nature of the task, higher WM capacity could lead to a better ability to inhibit the tendency to recall/recognize the highly familiar critical lure in an attempt to better achieve the task goal of avoiding the false alarms.

Even more surprising than the high intrusion and falserecognition rates of critical lures in the DRM paradigm is the fact that these memory decisions are often accompanied by recollective detail. For example, participants often assign critical lures more remember than know responses (e.g., Gallo et al., 1997; Gallo, Roediger \& McDermott, 2001). In the remember/know paradigm (Gardiner, 1988; Tulving, 1985), remember responses are given to an item if the retrieval of that item is accompanied by a more conscious recollection of previously experiencing that item (e.g., if contextual detail from the time of study can be retrieved). A know response, on the other hand, is given to an item if the phenomenology of the retrieval of the item is more based on a feeling of familiarity. It is interesting that critical lures would be remembered, since they are not presented during study, and false memories in other tasks usually lead to low levels of conscious recollection (and are often even treated as noise). Even more interesting is that critical lures are given remember responses at rates comparable to those of studied items (e.g., Gallo, McDermott, Percer \& Roediger, 2001; Gallo et al., 1997; Geraci \& McCabe, 2006; Seamon et al., 1998; but see Mather, Henkel \& Johnson, 1997).

Roediger and McDermott (1995) suggested that heightened semantic activation of the critical lures during encoding, and the subsequent ease with which they can be generated in recall or processed in recognition, lead to the highly vivid illusory recollections of the critical lures. This is consistent with Jacoby, Kelley and Dywan's (1989) attributionalanalysis-of-memory explanation, that the fluency with which an item can be brought to consciousness increases the likelihood that an individual will label the item as being remembered. Gallo, McDermott et al. (2001) describe how a process like this could even explain the misattribution of a critical lure to a particular modality or speaker. For instance, when a critical lure is processed fluently during testing and the contextual detail of experiencing the list of that lure's semantic associates is recollected vividly, participants will often misattribute this conscious recollection to the lure word itself. Furthermore, it follows that the stronger a critical lure's activation is during encoding, the greater the enhancement of these attribution processes during testing, leading to an increase in illusory recollections (e.g., a higher number of false remember responses). This is exactly what Gallo and Roediger (2003) found when they increased the length of the associative lists during study (which presumably strengthens the semantic activation of critical lures).

Analogous to the high false-recall and false-recognition rates in the DRM, the reliability of high rates of illusory recollection has led to great interest in potential variables that 
could at least reduce these rates. Gallo et al. (1997) found that when participants received a forewarning prior to encoding, this reduced the likelihood of critical lures being given remember responses. This is evidence that when participants are forewarned, they are able to use that information to aid in reducing the misattribution of recollective experience to the critical lures. Because a participant has to monitor the source of an item's fluent processing and recollective details, it would also be predicted that the levels of attentional resources available during testing would have an influence on the ability to attribute critical lures to their correct sources. Knott and Dewhurst (2007b, Exp. 2) found that divided attention during retrieval led to an increase in remember responses for critical lures, as compared to a full-attention condition. Presumably this need for attentional resources during retrieval for correct source attribution is increased when a forewarning is given, since the heightened knowledge of how the DRM illusion works will lead to greater attention being given to the source of an item's recollective experience.

In the present experiments, the influence that individual differences in WM capacity play in illusory recollection was investigated. Because of their robustness and reliability in producing high rates of illusory subjective experiences, DRM associative lists were used to elicit false memories. It was predicted that participants with higher WM capacity would have reduced illusory recollections of critical lures (as measured by their remember responses). This relationship should be present when a forewarning was given prior to encoding (Exp. 1), since forewarning increases the attentional demand of the task, as described above. However, this relationship between WM capacity and illusory recollection would be expected to be reduced or not present in the absence of a forewarning (Exp. 2). Previous research has shown that in the absence of a forewarning, WM capacity is not related to false recall or recognition of critical lures (Peters et al., 2007; Watson et al., 2005). Presumably, the standard list-learning processes during encoding and the standard retrieval processes during testing that are in place in the absence of a forewarning are not attentionally demanding enough for differences in WM capacity to have a large influence on performance.

\section{Experiment 1}

Method

\section{Participants}

A group of 39 undergraduates participated in the present experiment in exchange for partial course credit. The participants received instructions individually or in small groups, but were tested at individual workstations.

\section{Materials}

WM task An operation span (OSPAN) task modeled after that of Conway and Engle (1996) was used to measure WM capacity. An operation (e.g., "Is $(7 \times 1)+6=13$ ?") appeared on the computer monitor in black font on a white background. The participants read the operation aloud and used a mouse to click a "yes" button if the participant thought that the operation was true, and "no" if it was false. A word (e.g., "class") then appeared on the screen, and participants read the word out loud. They were instructed to remember the words for a later recognition test. After a set of two to six operations, participants were asked to recognize the words in the order of their presentation, and the list of words was displayed on the screen. The participants clicked the words in the order that they had been presented. The participants then clicked "Next Trial" to begin a new set of operations. Three operation sets were used for practice, and 15 operation sets (three for each set length) were then completed. The ordering of the operation sets was randomized, so participants were unaware of when a recognition test would occur on the basis of the length of the previous set.

To determine OSPAN score, we summed the correctly recognized set lengths (e.g., correct recognition of an operation set of three led to three points). The maximum score for the task was 60 . OSPAN scores were used in the analyses if the participant scored a minimum of $85 \%$ correct in evaluating the math operations. All of the participants in both experiments met this criterion.

False-memory task A version of the DRM was used to measure susceptibility to the creation of false memories. Six associative lists from Roediger and McDermott (1995, Exp. 1) were used. These six particular lists (sleep, rough, chair, mountain, needle, and sweet) had been found to elicit high intrusion and recognition rates of critical lures in experiments using the DRM paradigm (e.g., Deese, 1959; Gallo \& Roediger, 2002; Stadler, Roediger \& McDermott, 1999). According to the Stadler et al. (1999) norms, the mean recall rate of the critical lures for these six lists is .53 , and the mean false-recognition rate is .75 .

Each associative list contained 15 words that were presented individually on the left side of the computer monitor in black font on a white background for $1.5 \mathrm{~s}$. Following the presentation of each associative list, participants were prompted to recognize, in any order, the words from the previous list. Sixteen words were then displayed on the right side of the monitor. Seven were words from the previously presented list (studied words), eight were noncritical distractors (not presented and not semantically related to the previous list), and one word was the critical lure (semantically related to the previous list but was not presented). Participants used the mouse to click recognized words from the previously studied list. 


\section{Procedure}

The order of the OSPAN and DRM tasks was counterbalanced across groups. This resulted in 18 participants completing the OSPAN task first and 21 participants completing the DRM task first. Order had no effect on any of the dependent measures. For the OSPAN task, a brief tutorial (a replication of the instructions presented by the experimenter) on how to complete the task was presented on the computer monitor. After the tutorial, participants used the mouse to click a button labeled "Next Trial." Three sets of operations (with two operations per set) were then presented on the computer for practice. Following the practice sets, the 15 experimental sets were presented. For the DRM task, participants were instructed that they would be presented a series of lists that they were to memorize for a recognition test that would follow each list. Participants were forewarned of the tendency of associative lists used in the DRM paradigm to lead to false memories of critical lures. To ensure that participants understood the nature of the DRM task, they were provided with an example list and its associated critical lure. For each word that participants recognized as old, they were advised to make a remember or know judgment (Gardiner, 1988; Tulving, 1985). Descriptions and examples of remember/know judgments closely modeled after those of Rajaram (1993) were provided. Participants were told to write their remember/know judgments for each recognized item on provided sheets of paper.

\section{Results and discussion}

\section{Recognition}

Descriptive statistics for the recognition and working memory tasks are presented in Table 1 . Because of their nearfloor recognition rates, noncritical distractors were not included in any of the following analyses. Instead, we confined our focus to studied items and critical lures. To determine how WM capacity was related to recognition performance for the different items, a series of Pearson product-moment correlations were computed between OSPAN scores and recognition rates (see Table 2). No relationship was found between WM capacity and veridical recognition of studied items $(r=.04, p>.05)$. However, a significant negative relationship was found between WM capacity and false recognition of critical lures $(r=-.49, p<$ $.01)$. This negative correlation indicates that participants with higher WM capacity were more likely to produce lower rates of false recognition for critical lures.

Signal detection measures were also calculated from participants' recognition data (Macmillan \& Creelman,
2005). To measure sensitivity between the studied items and critical lures, $d^{\prime}$ was used. ${ }^{1}$ A significant relationship was found between WM capacity and recognition $d^{\prime}$ scores $(r=.53, p<.01)$. As Fig. 1a displays, participants with higher WM capacity were more likely to have greater sensitivity between studied items and critical lures during recognition.

\section{Remember/know}

The relationships between OSPAN and remember/know responses following recognition judgments are displayed in Table 2. For subjective experience following veridical recognition of studied items, WM capacity was not significantly related to the proportion of either remember responses $(r=-.11, p>.05)$ or know responses $(r=.17$, $p>.05)$.

Individual differences in WM capacity were found to be significantly related to the proportion of remember responses given to critical lures $(r=-.42, p<.01)$. This negative correlation indicates that higher WM capacity was associated with lower illusory recollection of critical lures. A remember $d^{\prime}$ score was calculated between remembered studied items and remembered critical lures and was also found to significantly relate to WM capacity $(r=.41, p<$ $.01)$. As Fig. 1b shows, higher WM capacity was associated with greater sensitivity in recollective experience between studied items and critical lures. The proportion of know responses for critical lures was not found to be significantly related to WM capacity $(r=.07, p>.05)$. This result, according to a process-pure interpretation of remember/know judgments, indicates that WM capacity was not related to levels of familiarity for critical lures. However, according to the independent remember-know model (Jacoby, Yonelinas \& Jennings, 1997), standard proportions of know responses underestimate the contribution of familiarity to recognition decisions. As a result, use of the correction know/(1 - remember $)$ has been advised, to more accurately compute levels of familiarity (Yonelinas \& Jacoby, 1995), since it conditionalizes the proportion of know responses for nonrecollected (i.e., non-remembered) items. This independent familiarity measure was related to WM capacity $(r=-.49$, $p<.01$ ), indicating that decreased familiarity (in addition to decreased recollection) for critical lures may have been associated with higher WM capacity.

\footnotetext{
${ }^{1}$ Here and in all other instances where $d^{\prime}$ is used, we also used $A^{\prime}$ as a sensitivity measure and found the same patterns of results. Moreover, for $d^{\prime}$ and other measures used in which hit or false alarm rates of 0 or 1 lead to infinite or undefined values, the correction $1 /(2 N)$ or $1-[1 /(2 N)]$ was applied (with $N$ equaling the number of trials that the particular proportion is based on; see Kadlec, 1999; Macmillan \& Creelman, 2005; Stanislaw \& Todorov, 1999).
} 
Table 1 Mean recognition rates and proportions of remember and know responses, with standard deviations (in parentheses), for studied words, noncritical distractors, and critical lures, with operation span (OSPAN) presented as mean overall scores

\begin{tabular}{lcll}
\hline & $M$ & $\mathrm{R}$ & $\mathrm{K}$ \\
\hline Experiment 1 & & & \\
Studied words & $.78(.13)$ & $.60(.18)$ & $.18(.13)$ \\
Noncritical distractors & $.02(.02)$ & $.01(.01)$ & $.01(.02)$ \\
Critical lures & $.68(.26)$ & $.43(.33)$ & $.25(.22)$ \\
OSPAN & $33.85(12.51)$ & & \\
Experiment 2 & & & \\
Studied words & $.80(.11)$ & $.62(.20)$ & $.18(.14)$ \\
Noncritical distractors & $.02(.02)$ & $.01(.01)$ & $.01(.02)$ \\
Critical lures & $.85(.15)$ & $.62(.26)$ & $.24(.22)$ \\
OSPAN & $33.95(13.40)$ & & \\
\hline
\end{tabular}

$\mathrm{R}$, remember judgment; $\mathrm{K}$, know judgment. Instances in which the $\mathrm{R}$ and $\mathrm{K}$ proportions do not sum to the overall proportion reflect rounding error

\section{Experiment 2}

The results of Experiment 1 showed that individual differences in WM capacity were related to recognition rates and illusory recollection for critical lure words. Importantly, all participants in Experiment 1 received a forewarning before encoding about the nature of the DRM illusion. It has been shown that forewarnings in DRM tasks increase the attentional demand of the task by leading participants to concurrently implement an identify-to-reject strategy during encoding (Gallo et al., 1997), resulting in influences of WM capacity on false-recall rates (Watson et al., 2005). In the absence of a forewarning, WM capacity has not been found to be associated with false-recall and false-recognition rates for critical lures (Peters et al., 2007; Watson et al., 2005).

Table 2 Bivariate correlations between working memory capacity (indexed by operation span [OSPAN]) and recognition and remember/know measures in both Experiments 1 and 2

\begin{tabular}{lcc}
\hline & $\begin{array}{c}\text { Experiment 1 } \\
\text { OSPAN }\end{array}$ & $\begin{array}{c}\text { Experiment 2 } \\
\text { OSPAN }\end{array}$ \\
\hline Studied words & .04 & .16 \\
Remember & -.11 & .28 \\
Know & .17 & -.26 \\
Critical lures & $-.49^{* *}$ & -.14 \\
Remember & $-.42^{* *}$ & -.04 \\
Know & .07 & -.05 \\
Independent & $-.49^{* *}$ & -.20 \\
$\quad$ familiarity & $.53^{* *}$ & .27 \\
Recognition $d^{\prime}$ & $.41^{* *}$ & .25 \\
Remember $d^{\prime}$ & &
\end{tabular}

${ }^{* *} p<.01 . N=39$ for all correlations
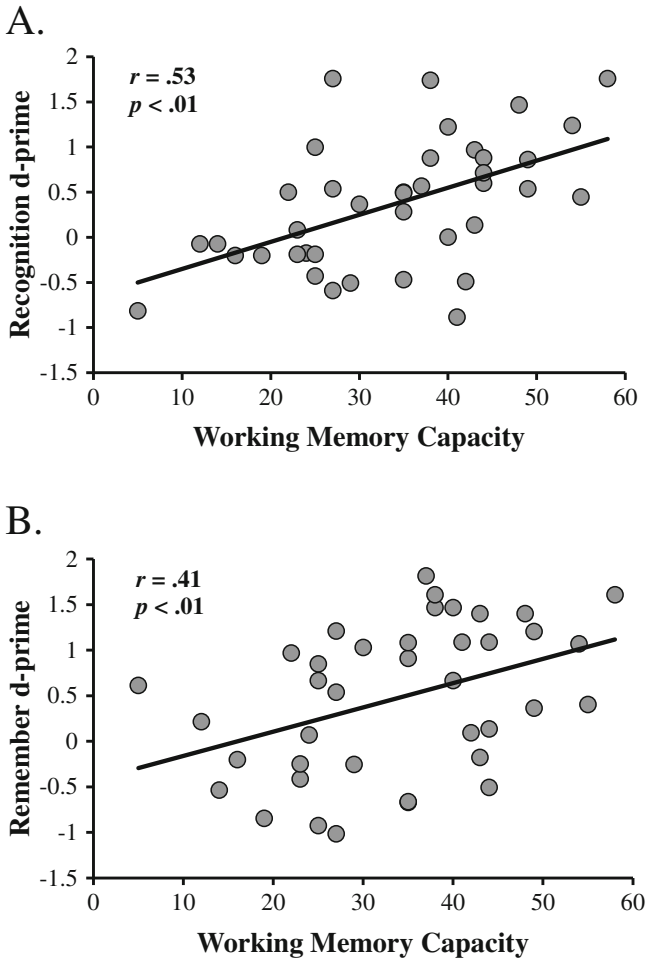

Fig. 1 The relationships between working memory capacity and recognition $d^{\prime}(\mathbf{a})$ and remember $d^{\prime}(\mathbf{b})$ in Experiment 1

For illusory recollection, it could be that in the absence of a forewarning, the level of attentional resources needed during testing (when attribution of recollective experience occurs) is not great enough for WM capacity differences to have an influence on performance. To investigate this possibility, the participants in Experiment 2 did not receive a forewarning, but instead were simply presented with the associative lists and then provided their recognition and remember/know judgments.

\section{Method}

\section{Participants}

A new sample of 41 undergraduates participated in the present experiment in exchange for partial course credit. The participants received instructions individually or in small groups, but were tested at individual workstations. The data from two participants who failed to follow directions were excluded from all of the following analyses.

\section{Materials and procedure}

The materials and procedure were the same as for Experiment 1, with the following exceptions. In Experiment 2, participants were not forewarned of the tendency of the DRM task to elicit false memories and were not provided with an example of a DRM list. Before presentation of the DRM lists, participants 
were simply told that they would be studying lists of words and would be taking a memory test after the presentation of each list. A group of 20 participants completed the OSPAN task first, and 21 participants completed the DRM task first. Order had no effect on any of the dependent measures.

\section{Results and discussion}

\section{Recognition}

Descriptive statistics for the recognition and WM tasks are presented in Table 1. As during Experiment 1, noncritical distractors were excluded from all analyses because of their near-floor recognition rates. Table 2 displays the Pearson product-moment correlations between OSPAN scores and recognition rates for the different items. As in Experiment 1, WM capacity was not related to veridical recognition of studied items $(r=.16, p>.05)$. In contrast to Experiment 1 , however, WM capacity was also not related to false recognition of critical lures $(r=-.14, p>.05)$. WM capacity was also not significantly related to the recognition signal detection measures. As Fig. 2a displays, although the relationship between WM capacity and recognition $d^{\prime}$ 'scores was in the same direction as for Experiment 1, the correlation between WM capacity and sensitivity between studied items and critical lures failed to reach significance $(r=.27, p>.05)$.
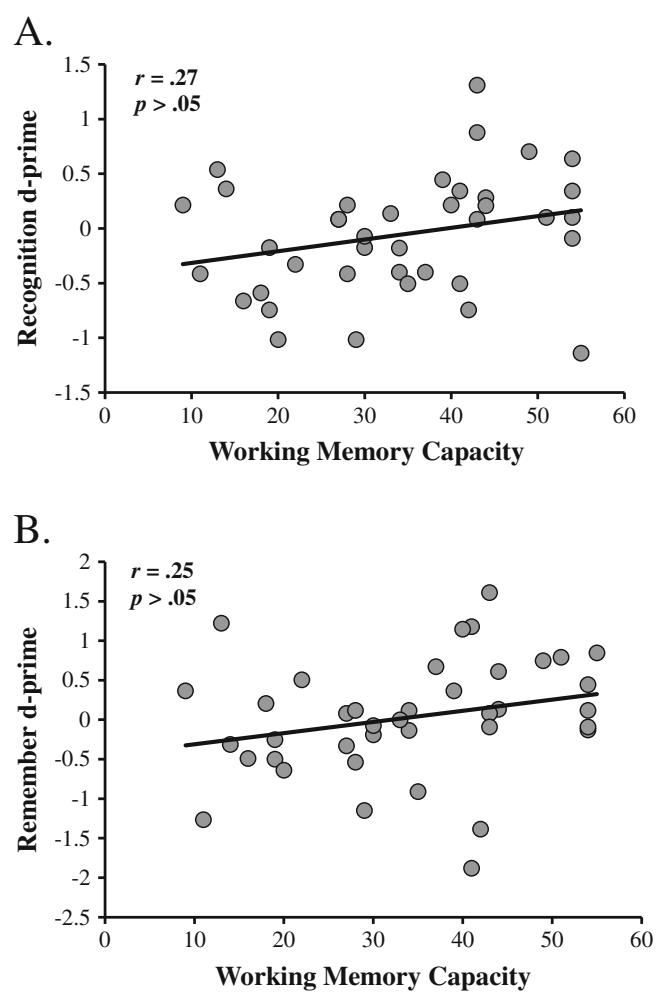

Fig. 2 The relationships between working memory capacity and recognition $d^{\prime}(\mathbf{a})$ and remember $d^{\prime}(\mathbf{b})$ in Experiment 2

\section{Remember/know}

WM capacity was marginally positively related to proportions of remember responses given to studied items $(r=.28$, $p<.09$ ). The relationship with know responses was in the opposite direction but did not quite reach marginal significance $(r=-.26, p<.11)$. The relationships between WM capacity and the three subjective experience measures for critical lures (remember responses, know responses, and independent familiarity) were all negative but failed to reach significance (all $p \mathrm{~s}>.21$ ). Finally, the relationship between WM capacity and remember $d^{\prime}$ did not reach significance $(r=$ $.25, p=.12$ ). As Fig. $2 \mathrm{~b}$ shows, although the relationship between WM capacity and remember $d^{\prime}$ scores was in the same direction as for Experiment 1, the correlation between WM capacity and sensitivity in recollective experience between studied items and critical lures in the absence of a forewarning failed to reach acceptable levels of significance.

\section{Cross-experimental analyses}

The only difference between Experiments 1 and 2 was that participants in Experiment 1 were forewarned of the tendency of the DRM to elicit false memories and were provided with a sample DRM list. To test statistically how this forewarning interacted with WM capacity to influence both false recognition and illusory recollection of critical lures, we pooled the data across both experiments. A multivariate analysis of covariance (MANCOVA) was run with Experiment (i.e., forewarning) as a fixed factor and OSPAN as a covariate. The dependent measures included false-recognition rates for the critical lures and the proportions of remember and know responses given to critical lures. An interaction term between experiment and OSPAN was included to determine whether the relationships between OSPAN and the various dependent measures were significantly different between the two experiments.

The interaction between experiment and OSPAN on criticallure recognition rates was significant $[F(1,74)=6.19, p<.05]$. This indicates that the slopes of the regression lines between OSPAN and false recognition of critical lures differed significantly, depending on the presence or absence of the forewarning. Specifically, the negative correlation between OSPAN and false-recognition rates of critical lures was stronger when a forewarning was given. For critical-lure remember responses, the interaction between experiment and OSPAN also reached significance $[F(1,74)=4.25, p<.05]$. Once again, this indicates that the slopes of the regression lines between OSPAN and critical-lure remember responses differed depending on the presence of the forewarning. As with the false-recognition rates, the negative correlation between OSPAN and criticallure remember responses was stronger when a forewarning was given. Experiment and OSPAN did not interact to influence critical-lure know responses $(F<1)$, indicating no difference in 
the relations between OSPAN and critical-lure know responses across the two experiments.

\section{General discussion}

The relationship between individual differences in WM capacity and susceptibility to illusory recollections was investigated in the present study. DRM associative lists were used to elicit false memories and illusory recollections, as measured by remember/know judgments. We found that WM capacity was associated with recollective experience of critical lures, in that participants with higher WM capacity had lower illusory recollection of critical lure words (as measured by their remember responses). However, this relationship was only present when an explicit forewarning of the nature of the DRM task was given to participants prior to encoding. When this forewarning was absent, we found no significant relationship between WM capacity and illusory recollection of the DRM critical lures.

An identify-to-reject strategy has been used to explain the effect of forewarnings on reducing false recall and recognition in the DRM paradigm. According to this strategy, participants attempt to identify the critical lure of a list during encoding, which aids in correctly rejecting the critical lure during testing. Gallo et al. (1997) found that a plurality of forewarned participants self-reported using an identify-to-reject strategy. It has also been found that forewarnings reduce false recognitions more for DRM lists with critical lures that are more highly identifiable (Neuschatz et al., 2003). Furthermore, when certain task constraints that disrupt the ability to implement an identify-to-reject strategy are added to a DRM task (e.g., high presentation rate), false-recognition rates of critical lures increase (Carneiro et al., 2012). Differences in the ability to effectively implement an identify-to-reject strategy could explain the effect of WM capacity on false recognition of critical lures found in Experiment 1 of the present study. However, it is not yet clear where in the task this difference would emerge. That is, individuals with higher WM capacity may be better able to identify critical lures during encoding, since in order to identify the critical lure, one has to concurrently process the words of a list for the subsequent memory test while trying to extract the theme of the list. However, it may be that individuals across the distribution of WM capacity can similarly identify critical lures during list encoding, but that individuals with higher WM capacity are better able to retain that identification later during testing, when identification can aid in correct source monitoring. Future research will be needed to explore possible WM differences in the ability to implement identify-to-reject strategies in the DRM and other falsememory paradigms.

Previous research has shown that forewarnings reduce the proportion of remember responses given to critical lures in DRM tasks (e.g., Gallo et al., 1997). The results of the present study extend prior research by showing that this reduction is not exhibited equally across the distribution of WM capacity. Because the inclusion of a forewarning increases the attentional demand of the DRM task, it is understandable why individuals with higher WM capacity would be better able to correctly monitor the source of critical lures and be less likely to attribute recollective experience to them. This finding is also consistent with studies that have shown that differential WM effects on performance are most reliably found in situations in which the task goals need to be actively maintained in the presence of attention-demanding distraction (especially if the distraction leads to a habitual response that needs to be inhibited to achieve a task goal; Conway, Cowan \& Bunting, 2001; Kane \& Engle, 2003; Long \& Prat, 2002). It is reasonable to assume that because critical lures are so fluently and easily brought to consciousness during retrieval in the DRM, the use of a forewarning to allow the participant to better inhibit the tendency to attribute recollection to critical lures would more likely occur among individuals with higher WM capacity.

The general findings of the present research can be compared to those from research on the effect of attentional manipulations during encoding and retrieval in the DRM and in other list-learning paradigms (e.g., Dehon, 2006; Otgaar, Peters \& Howe, 2012; Pérez-Mata, Read \& Diges, 2002; Seamon, Goodkind, Dumey, Dick, Aufseeser, Strickland \& Fung, 2003; Skinner \& Fernandes, 2008, 2009). For example, Knott and Dewhurst (2007b, Exp. 2) found that divided attention during retrieval led to an increase in remember responses for critical lures as compared to a full-attention condition, in that participants simply completed the recognition test without any additional cognitive load (for similar patterns of results, but in different paradigms, see Dudukovic, DuBrow \& Wagner, 2009; Knott \& Dewhurst, 2007a, Exp. 2; Skinner \& Fernandes, 2008). ${ }^{2}$ Peters, Jelicic, Gorski, Sijstermans, Giesbrecht and Merckelbach (2008) crossed a forewarning manipulation with a divided-attention manipulation and found

\footnotetext{
${ }^{2}$ The relationship is less clear between divided attention during encoding and both false recall and false recognition. Otgaar et al. (2012) found that divided attention led to increased levels of false recall for adults, but decreased levels for children. Pérez-Mata et al. (2002) also found increased levels of false-recall rates when attention was divided. Seamon et al. (2003), on the other hand, found no effect on false-recall rates, and Knott and Dewhurst (2007b, Exp. 1) actually found a decrease in false-recognition rates (and remember responses) for critical lures. However, the different procedures used in these studies make any direct comparison between their results difficult. Depending on the difficulty of a secondary or concurrent task during DRM list encoding, very different patterns of results would be expected. For instance, if a secondary task was difficult enough to disrupt the activation of the semantic list networks during encoding, decreased levels of false alarms and illusory recollections would be expected. However, a weaker secondary task could leave the activation of critical lures during encoding intact, but be difficult enough to impair successful source monitoring and attribution during testing. In this case, an increase in false alarms and illusory recollections would be expected.
} 
that only participants in the full-attention condition were able to use the forewarning to reduce false recall of critical lures. However, no subjective recollection measures were included in the Peters et al. (2008) study, so it is not known how forewarning interacted with the attentional manipulation to affect illusory recollective experiences. However, the results of Knott and Dewhurst (2007b) showed that the attribution of recollective experience to its correct source during testing can require the presence of controlled attention. This is especially the case when a forewarning is given, since it increases the attentional demands of a task like the DRM during both encoding (when an identify-to-reject strategy occurs concurrently with standard list-learning processes) and retrieval (when a heightened awareness of the DRM illusion leads to more attention being given to source monitoring and attribution processes). This increased need for attentional resources is presumably what led participants with higher WM capacity in the present research to have reduced amounts of illusory recollections when forewarned.

The discussion of the remember/know results above assumes a dual-process interpretation of these judgments (e.g., Yonelinas, 2002), in which remember responses are a measure of recollection, and know responses are a measure of familiarity. Other interpretations of these judgments are available, however, based on signal detection theory (e.g., Dunn, 2004, 2008; Rotello, Macmillan \& Reeder, 2004; Wixted \& Mickes, 2010; Wixted \& Stretch, 2004). For instance, according to a dual-process signal detection model (Wixted, 2007), recollection and familiarity are continuous processes that get aggregated on a unidimensional strength axis with different criteria for remember and know judgments (for recent evidence that recollection is better conceived of as a graded, continuous process, see Mickes, Wais \& Wixted, 2009; Slotnick, 2010). This suggests that participants will provide a remember response when memory strength for the item being tested is high (stemming from the aggregation of recollection and familiarity for the item). For the results of Experiment 1 in the present study, this would mean that the negative relationship between WM capacity and remember responses for critical lures stemmed from lower WM capacity being associated with stronger subjective memories for critical lures. However, even though these various models differ in their interpretation of remember/know findings, it is still agreed that remember responses are usually accompanied by recollection. As evidence, think-aloud protocols have revealed that the vast majority of remember responses are associated with recollective detail from encoding/study (McCabe, Geraci, Boman, Sensenig \& Rhodes, 2011). As a result, the relationship between WM capacity and remember responses to critical lures in Experiment 1 of the present research can confidently be said to have stemmed, at least in part, from differences in illusory recollection of the falsely recognized critical lures.
The above debate over whether remember/know judgments are process-pure measures of recollection and familiarity makes it important for future research to determine whether the results of the present study apply to other measures of subjective experience. For instance, DRM false memories have been found to be accompanied by various phenomenal characteristics, such as qualitative details (Mather et al., 1997) and modality/source attributions (e.g., Payne, Elie, Blackwell \& Neuschatz, 1996; Roediger, McDermott, Pisoni \& Gallo, 2004). It will be important to determine how individual differences in WM capacity influence these other subjective measures of illusory memories, and under what conditions (e.g., when a forewarning is absent or present). Furthermore, WM capacity has been found to be related to other false-memory paradigms and effects, such as the misinformation effect (Gerrie \& Garry, 2007; Jaschinkski \& Wentura, 2002) and memory conjunction errors (Reinitz \& Hannigan, 2004). It will be important to determine how individual differences in WM capacity relate to phenomenological characteristics of these false memories, as well. In that way, a more global picture of how WM capacity influences illusory recollective experience can be developed.

Author note The authors thank Nesina Kritikos and Nicole Peterson for help with the data collection.

\section{References}

Carneiro, P., Fernandez, A., Diez, E., Garcia-Marques, L., Ramos, T., \& Ferreira, M. B. (2012). "Identify-to-reject": A specific strategy to avoid false memories in the DRM paradigm. Memory \& Cognition, 40, 252-265. doi:10.3758/s13421-011-0152-6

Colflesh, G. J. H., \& Conway, A. R. A. (2007). Individual differences in working memory capacity and divided attention in dichotic listening. Psychonomic Bulletin \& Review, 14, 699-703.

Conway, A. R. A., Cowan, N., \& Bunting, M. F. (2001). The cocktail party phenomenon revisited: The importance of working memory capacity. Psychonomic Bulletin \& Review, 8, 331-335. doi:10.3758/ BF03196169

Conway, A. R. A., \& Engle, R. W. (1996). Individual differences in working memory capacity: More evidence for a general capacity theory. Memory, 4, 577-590. doi:10.1080/741940997

Deese, J. (1959). On the prediction of occurrence of particular verbal intrusions in immediate recall. Journal of Experimental Psychology, 58, 17-22. doi:10.1037/h0046671

Dehon, H. (2006). Variations in processing resources and resistance to false memories in younger and older adults. Memory, 14, 692711. doi:10.1080/09658210600648456

Dudukovic, N. M., DuBrow, S., \& Wagner, A. D. (2009). Attention during memory retrieval enhances future remembering. Memory \& Cognition, 37, 953-961. doi:10.3758/MC.37.7.953

Dunn, J. C. (2004). Remember-know: A matter of confidence. Psychological Review, 111, 524-542. doi:10.1037/0033-295X.111.2.524

Dunn, J. C. (2008). The dimensionality of the remember-know task: A state-trace analysis. Psychological Review, 115, 426-446. doi:10.1037/0033-295X.115.2.426 
Engle, R. W., \& Kane, M. J. (2004). Executive attention, working memory capacity, and a two-factor theory of cognitive control. In B. H. Ross (Ed.), The psychology of learning and motivation (Vol. 44, pp. 145-199). New York: Academic Press.

Gallo, D. A. (2010). False memories and fantastic beliefs: 15 years of the DRM illusion. Memory \& Cognition, 38, 833-848. doi:10.3758/ MC.38.7.833

Gallo, D. A., McDermott, K. B., Percer, J. M., \& Roediger, H. L., III. (2001). Modality effects in false recall and false recognition. Journal of Experimental Psychology: Learning, Memory, and Cognition, 27, 339-353. doi:10.1037/0278-7393.27.2.339

Gallo, D. A., Roberts, M. J., \& Seamon, J. G. (1997). Remembering words not presented in lists: Can we avoid creating false memories? Psychonomic Bulletin \& Review, 4, 271-276. doi:10.3758/ BF03209405

Gallo, D. A., \& Roediger, H. L., III. (2002). Variability among word lists in eliciting memory illusions: Evidence for associative activation and monitoring. Journal of Memory and Language, 47, 469-497.

Gallo, D. A., \& Roediger, H. L., III. (2003). The effects of associations and aging on illusory recollection. Memory \& Cognition, 31, 1036-1044. doi:10.3758/BF03196124

Gallo, D. A., Roediger, H. L., III, \& McDermott, K. B. (2001). Associative false recognition occurs without strategic criterion shifts. Psychonomic Bulletin \& Review, 8, 579-586. doi:10.3758/ BF03196194

Gardiner, J. M. (1988). Functional aspects of recollective experience. Memory \& Cognition, 16, 309-313. doi:10.3758/BF03197041

Geraci, L., \& McCabe, D. P. (2006). Examining the basis for illusory recollection: The role of remember/know instructions. Psychonomic Bulletin \& Review, 13, 466-473. doi:10.3758/BF03193871

Gerrie, M. P., \& Garry, M. (2007). Individual differences in working memory capacity affect false memories for missing aspects of events. Memory, 15, 561-571. doi:10.1080/09658210701391634

Hicks, J. L., \& Hancock, T. W. (2002). Backward associative strength determines source attributions given to false memories. Psychonomic Bulletin \& Review, 9, 807-815.

Jacoby, L. L., Kelley, C. M., \& Dywan, J. (1989). Memory attributions. In H. L. Roediger III \& F. I. M. Craik (Eds.), Varieties of memory and consciousness: Essays in honor of Endel Tulving (pp. 391422). Hillsdale: Erlbaum.

Jacoby, L. L., Yonelinas, A. P., \& Jennings, J. M. (1997). The relation between conscious and unconscious (automatic) influences: A declaration of independence. In J. D. Cohen \& J. W. Schooler (Eds.), Scientific approaches to consciousness (pp. 13-47). Hillsdale: Erlbaum.

Jaschinkski, U., \& Wentura, D. (2002). Misleading postevent information and working memory capacity: An individual differences approach of eye-witness memory. Applied Cognitive Psychology, $16,223-231$.

Johnson, M. K., Hashtroudi, S., \& Lindsay, D. S. (1993). Source monitoring. Psychological Bulletin, 114, 3-28. doi:10.1037/ 0033-2909.114.1.3

Johnson, M. K., \& Raye, C. L. (1981). Reality monitoring. Psychological Review, 88, 67-85. doi:10.1037/0033-295X.88.1.67

Kadlec, H. (1999). Statistical properties of $d^{\prime}$ and $\beta$ estimates of signal detection theory. Psychological Methods, 4, 22-43. doi:10.1037/ 1082-989X.4.1.22

Kane, M. J., \& Engle, R. W. (2002). The role of prefrontal cortex in working-memory capacity, executive attention, and general fluid intelligence: An individual-differences perspective. Psychonomic Bulletin \& Review, 9, 637-671. doi:10.3758/BF03196323

Kane, M. J., \& Engle, R. W. (2003). Working-memory capacity and the control of attention: The contributions of goal neglect, response competition, and task set to Stroop interference. Journal of Experimental Psychology. General, 132, 47-70. doi:10.1037/00963445.132.1.47
Knott, L. M., \& Dewhurst, S. A. (2007a). Divided attention at retrieval disrupts knowing but not remembering. Memory, 15, 664-674. doi:10.1080/09658210701467137

Knott, L. M., \& Dewhurst, S. A. (2007b). The effects of divided attention at study and test on false recognition: A comparison of DRM and categorized lists. Memory \& Cognition, 35, 1954 1965. doi:10.3758/BF03192928

Long, D. L., \& Prat, C. S. (2002). Working memory and Stroop interference: An individual differences investigation. Memory \& Cognition, 30, 294-301. doi:10.3758/BF03195290

Macmillan, N. A., \& Creelman, C. D. (2005). Detection theory: A user's guide (2nd ed.). Mahwah: Erlbaum.

Mather, M., Henkel, L. A., \& Johnson, M. K. (1997). Evaluating characteristics of false memories: Remember/know judgments and memory characteristics questionnaire compared. Memory \& Cognition, 25, 826-837. doi:10.3758/BF03211327

McCabe, D. P., Geraci, L., Boman, J. K., Sensenig, A. E., \& Rhodes, M. G. (2011). On the validity of remember-know judgments: Evidence from think aloud protocols. Consciousness and Cognition, 20, 1625-1633. doi:10.1016/j.concog.2011.08.012

McDermott, K. B. (1996). The persistence of false memories in list recall. Journal of Memory and Language, 35, 212-230. doi:10.1006/jmla.1996.0012

McDermott, K. B., \& Roediger, H. L., III. (1998). Attempting to avoid illusory memories: Robust false recognition of associates persists under conditions of explicit warnings and immediate testing. Journal of Memory and Language, 39, 508-520. doi:10.1006/ jmla.1998.2582

Mickes, L., Wais, P. E., \& Wixted, J. T. (2009). Recollection is a continuous process: Implications for dual-process theories of recognition memory. Psychological Science, 20, 509-515. doi:10.1111/j.1467-9280.2009.02324.x

Neuschatz, J. S., Benoit, G. E., \& Payne, D. G. (2003). Effective warnings in the Deese-Roediger-McDermott false-memory paradigm: The role of identifiability. Journal of Experimental Psychology: Learning, Memory, and Cognition, 29, 35-40. doi:10.1037/0278-7393.29.1.35

Otgaar, H., Peters, M., \& Howe, M. L. (2012). Dividing attention lowers children's but increases adults' false memories. Journal of Experimental Psychology: Learning, Memory, and Cognition, 38, 204-210. doi:10.1037/a0025160

Payne, D. G., Elie, C. J., Blackwell, J. M., \& Neuschatz, J. S. (1996). Memory illusions: Recalling, recognizing, and recollecting events that never occurred. Journal of Memory and Language, 35, 261-285.

Pérez-Mata, M. N., Read, J. D., \& Diges, M. (2002). Effects of divided attention and word concreteness on correct recall and false memory reports. Memory, 10, 161-177.

Peters, M. J. V., Jelicic, M., Gorski, B., Sijstermans, K., Giesbrecht, T., \& Merckelbach, H. (2008). The corrective effects of warning on false memories in the DRM paradigm are limited to full attention conditions. Acta Psychologica, 129, 308-314. doi:10.1016/ j.actpsy.2008.08.007

Peters, M. J. V., Jelicic, M., Verbeek, H., \& Merckelbach, H. (2007). Poor working memory predicts false memories. European Journal of Cognitive Psychology, 19, 213-232.

Rajaram, S. (1993). Remembering and knowing: Two means of access to the personal past. Memory \& Cognition, 21, 89-102. doi:10.3758/BF03211168

Reinitz, M. T., \& Hannigan, S. L. (2004). False memories for compound words: Role of working memory. Memory \& Cognition, $32,463-473$.

Roediger, H. L., III, \& McDermott, K. B. (1995). Creating false memories: Remembering words not presented in lists. Journal of Experimental Psychology: Learning, Memory, and Cognition, 21, 803-814. doi:10.1037/0278-7393.21.4.803 
Roediger, H. L., III, \& McDermott, K. B. (2000). Tricks of memory. Current Directions in Psychological Science, 9, 123-127.

Roediger, H. L., III, McDermott, K. B., Pisoni, D. B., \& Gallo, D. A. (2004). Illusory recollection of voices. Memory, 12, 586-602. doi:10.1080/09658210344000125

Roediger, H. L., III, Watson, J. M., McDermott, K. B., \& Gallo, D. A. (2001). Factors that determine false recall: A multiple regression analysis. Psychonomic Bulletin \& Review, 8, 385-407. doi:10.3758/BF03196177

Rotello, C. M., Macmillan, N. A., \& Reeder, J. A. (2004). Sumdifference theory of remembering and knowing: A twodimensional signal-detection model. Psychological Review, 111, 588-616. doi:10.1037/0033-295X.111.3.588

Seamon, J. G., Goodkind, M. S., Dumey, A. D., Dick, E., Aufseeser, M. S., Strickland, S. E., \& Fung, N. S. (2003). "If I didn't write it, why would I remember it?" Effects of encoding, attention, and practice on accurate and false memory. Memory \& Cognition, 31, 445-457. doi:10.3758/BF03194402

Seamon, J. G., Luo, C. R., \& Gallo, D. A. (1998). Creating false memories of words with or without recognition of list items: Evidence for nonconscious processes. Psychological Science, 9, 20-26.

Skinner, E. I., \& Fernandes, M. A. (2008). Interfering with remembering and knowing: Effects of divided attention at retrieval. Acta Psychologica, 127, 211-221. doi:10.1016/j.actpsy.2007.05.001

Skinner, E. I., \& Fernandes, M. A. (2009). Illusory recollection in older adults and younger adults under divided attention. Psychology and Aging, 24, 211-216. doi:10.1037/a0014177

Slotnick, S. D. (2010). "Remember" source memory ROCs indicate recollection is a continuous process. Memory, 18, 27-39. doi: 10.1080/09658210903390061

Stadler, M. A., Roediger, H. L., III, \& McDermott, K. B. (1999). Norms for word lists that create false memories. Memory \& Cognition, 27, 494-500. doi:10.3758/BF03211543
Stanislaw, H., \& Todorov, N. (1999). Calculation of signal detection theory measures. Behavior Research Methods, Instruments, \& Computers, 31, 137-149. doi:10.3758/BF03207704

Tulving, E. (1985). Memory and consciousness. Canadian Psychology, 26, 1-12. doi:10.1037/h0080017

Underwood, B. J. (1965). False recognition produced by implicit verbal responses. Journal of Experimental Psychology, 70, 122129. doi: $10.1037 / \mathrm{h} 0022014$

Watson, J. M., Bunting, M. F., Poole, B. J., \& Conway, A. R. A. (2005). Individual differences in susceptibility to false memory in the Deese-Roediger-McDermott paradigm. Journal of Experimental Psychology: Learning, Memory, and Cognition, 31, 7685. doi: $10.1037 / 0278-7393.31 .1 .76$

Watson, J. M., McDermott, K. B., \& Balota, D. A. (2004). Attempting to avoid false memories in the Deese/Roediger-McDermott paradigm: Assessing the combined influence of practice and warnings in young and old adults. Memory \& Cognition, 32, 135-141. doi: $10.3758 / \mathrm{BF} 03195826$

Wixted, J. T. (2007). Dual-process theory and signal-detection theory of recognition memory. Psychological Review, 114, 152-176. doi:10.1037/0033-295X.114.1.152

Wixted, J. T., \& Mickes, L. (2010). A continuous dual-process model of remember/know judgments. Psychological Review, 117, 10251054. doi:10.1037/a0020874

Wixted, J. T., \& Stretch, V. (2004). In defense of the signal detection interpretation of remember/know judgments. Psychonomic Bulletin \& Review, 11, 616-641. doi:10.3758/BF03196616

Yonelinas, A. P. (2002). The nature of recollection and familiarity: A review of 30 years of research. Journal of Memory and Language, 46, 441-517. doi:10.1006/jmla.2002.2864

Yonelinas, A. P., \& Jacoby, L. L. (1995). The relation between remembering and knowing as bases for recognition: Effects of size congruency. Journal of Memory and Language, 34, 622-643. doi:10.1006/jmla.1995.1028 